\title{
A prospective study of cost, patient satisfaction, and outcome of treatment of chalazion by medical and nursing staff
}

\author{
T L Jackson, L Beun
}

\begin{abstract}
Aim-To study prospectively the outcome of conservative and surgical treatment of chalazia provided by medical and nursing staff.

Methods-During a 5 month recruitment period all patients attending a district general eye hospital for treatment of chalazion were included in the study. 129 patients (217 visits) with chalazia were seen by either a senior nurse or a trainee ophthalmologist (senior house officer, SHO) or both. Patients received either conservative treatment or eversion of the eyelid with incision and curettage. Patients were mailed a questionnaire asking them if their cyst had resolved and how they rated their treatment. Marginal cost analysis was used to determine the cost of treatment.
\end{abstract}

Results-The outcome of treatment could be determined in 170 of the 217 visits. Conservative treatment was successful for $29 \%$ of cysts while surgical treatment was successful for $72 \%$. There was no significant difference in treatment outcome between nurse and SHO groups. Patients found nurse treatment acceptable with a high level of patient satisfaction. The marginal cost of treatment by a nurse was $£ 9.91$ per cyst compared with $£ 12.10$ for SHOs. There were no surgical complications and no evidence of malignancy in six biopsies.

Conclusions-Surgical treatment of chalazion is safe and effective and successfully treats approximately three quarters of selected cysts. With conservative treatment approximately one third of selected chalazia will resolve within 3 months. Nurse treatment of chalazion is safe, effective, and acceptable to patients. (Br F Ophthalmol 2000;84:782-785)

The Sussex Eye Hospital, Brighton T L Jackson

L Beun

Correspondence to: Mr Tim Jackson, Academic Department of

Ophthalmology, The Rayne Institute, St Thomas's

Hospital, Lambeth Palace

Road, London SE1 7EH

TimLJackson@hotmail.com

Accepted for publication 24 February 2000
Despite being one of the commonest ophthalmic conditions ${ }^{1}$ there are very few large prospective studies of the treatment of chalazion. ${ }^{2}$ A number of relatively small trials have variably estimated the success of conventional surgical treatment of chalazion to range between $60-89 \%^{2-4}$ while conservative treatment may be successful for $25-77 \%$ of cysts. ${ }^{5-8}$ Without large prospective trials it is difficult to advise patients of the relative risks and benefits of surgical or conservative treatment.

This study was initiated at a time when a senior ophthalmic nurse (LB) began treating patients with chalazion. We are aware of nurse treatment of chalazion in other British centres ${ }^{9}$ but we do not know of any large, prospective studies on its success or safety. Without such studies hospital managers and clinicians may find it difficult to justify the delegation of treatment to non-medical staff.

By the use of a postal questionnaire this study prospectively followed the outcome of treatment provided concurrently by both nurse and trainee ophthalmologists (senior house officer; SHO). We also assessed various aspects of patient satisfaction. Marginal cost analysis was used to determine the cost of conservative and surgical treatment. This is the first, large prospective study we are aware of that analyses the outcome of treatment for all patients attending with chalazion thereby investigating both surgical and conservative treatment strategies. It is also the first, large prospective clinical study we know of that reports on nurse treatment of chalazion.

\section{Materials and methods}

During a 5 month recruitment period (January to May 1995) all patients attending a district general eye hospital for treatment of chalazion were included in the study. Patients were followed up until December 1995.

Although this study was not primarily designed to compare nurse and SHO treatment, the outcome of treatment data were analysed separately for comparison. Nurse and SHO cyst treatment clinics were run independently of one another and general practitioner referrals and eye casualty patients with chalazia were allocated to the next available clinic without consideration of whether this was run by a nurse or SHO. For the purposes of comparison those patients who were referred to senior medical staff for treatment of concomitant pathology such as rosacea remained in the original study group - that is, nurse or SHO. Patients who reattended with recurrent chalazion were reallocated to the next available clinic; hence, some patients were seen consecutively by both a nurse and SHO.

Nurse education in the conservative and surgical treatment of chalazia was provided by a consultant ophthalmologist and included instruction in the recognition of malignant lid lesions. A treatment protocol was designed to allow the nurse to practise independently but her clinic was run at time when senior medical staff were available for consultation.

Conservative treatment included patient advice about steam bathing of the eyelids and dispensing of chloramphenicol ointment to use 
Table 1 Patient profile

\begin{tabular}{lllll}
\hline & $\begin{array}{l}\text { Patients treated } \\
\text { exclusively by } \\
\text { nurse }\end{array}$ & $\begin{array}{l}\text { Patients treated } \\
\text { exclusively by a } \\
\text { SHO }\end{array}$ & $\begin{array}{l}\text { Patients seen } \\
\text { consecutively by both } \\
\text { nurse and SHO }\end{array}$ & $p$ Value \\
\hline Male (n) & 37 & 16 & 15 & 0.125 \\
Female(n) & 23 & 23 & 15 & 0.492 \\
Median age (range) & $44(18-76)$ & $43(14-82)$ & $47(16-82)$ & 0.445 \\
Median duration of symptoms in months (range) & $3.0(0.13-24)$ & $4.0(0.06-48)$ & $2.0(0.6-12)$ & \\
\hline
\end{tabular}

four times daily for 1 week. Surgical treatment involved 2\% lignocaine with 1:10 000 adrenaline dermal anaesthesia, eversion of the eyelid with a cyst clamp, and incision and curettage of the cyst contents (I\&C). Patients were kept in clinic until any bleeding had stopped and given chloramphenicol ointment to use four times daily for 1 week.

Patients were mailed a questionnaire asking them if their cyst had resolved completely or if it had become so small that it did not bother them. Those who did not respond were sent the questionnaire again and contacted by phone. Patients were asked to rate how adequately their treatment and diagnosis was explained and those who had I\&C were asked to indicate how uncomfortable the procedure had been using an unmarked $10 \mathrm{~cm}$ visual analogue scale with "no pain" at $0 \mathrm{~cm}$ and "the worst pain imaginable" at $10 \mathrm{~cm}$. Finally, patients were asked to give an overall rating for their treatment

The outcome of treatment was taken to be successful if the patient completed the questionnaire stating that their cyst had resolved completely or had become so small that it did not bother them. Treatment was defined as failed if a patient returned the questionnaire confirming that the cyst remained bothersome for more than 3 months or if they re-presented at any time within the 12 month study period complaining of a persisting chalazion. The Mann-Whitney $U$ test and the $\chi^{2}$ test were used and $\mathrm{p}$ values at the 0.05 level were considered significant.

The marginal cost of treatment was calculated by taking the total cost of treating all patients, divided by the number of patients treated (cost per patient treated), and the number of cysts treated (cost per cyst treated). These costs included wages, disposables, topi-

Table 2 Outcome of treatment by doctor and nurse after first visit in those patients with known clinical outcome

\begin{tabular}{lllc}
\hline & $\begin{array}{l}\text { Patients treated exclusively } \\
\text { by a nurse } \\
\text { Success rate } \\
\text { (Patient numbers) }\end{array}$ & $\begin{array}{l}\text { Patients treated exclusively } \\
\text { by an SHO } \\
\text { Success rate } \\
\text { (Patient numbers) }\end{array}$ & p Value \\
\hline Treatment & $43 \%(28)$ & $13 \%(23)$ & 0.030 \\
Sonservative treatment & $64 \%(28)$ & $83 \%(18)$ & 0.197 \\
Overall success & $54 \%(56)$ & $44 \%(41)$ & 0.413 \\
\hline
\end{tabular}

Table 3 Outcome of treatment after the first visit with IE C and conservative groups combined and including those patients lost to follow up (patient numbers)

\begin{tabular}{llll}
\hline Outcome of treatment & Nurse treatment & SHO treatment & Total \\
\hline Success & 30 & 18 & 48 \\
Lost to follow up & 19 & 13 & 32 \\
Failure & 26 & 23 & 49 \\
Total & 75 & 54 & 129 \\
\hline
\end{tabular}

cal and systemic antibiotics, dispensing, histology, and treatment pattern.

\section{Results}

For 129 patients with chalazia there were 217 hospital visits, 89 with a doctor and 128 with a nurse. Of these patients, 101 completed the questionnaire and the success or failure of treatment could be determined in 170 of the 217 visits. Patient profiles are shown in Table 1. There were no significant differences in age, sex, or duration of symptoms when comparing nurse and SHO treatment groups.

None of the patients was known to be diabetic and the clinical suspicion that diabetics are more prone to chalazion is not supported by this study. Six samples were sent for histology and none of these showed evidence of malignancy.

\section{CLINICAL OUTCOME}

Analysis of the success or failure of treatment at the patient's first visit showed that $72 \%$ of selected chalazia were successfully treated by I\&C and $29 \%$ of those treated conservatively resolved within 3 months.

On the first visit nurse treatment had a significantly higher success rate than SHOs with conservative treatment, while SHOs had a higher success rate with I\&C although this difference was not significant (Table 2).

After the first attendance the outcome of treatment could be determined for 97 out of 129 patients (Table 3). Assuming that success was a better outcome than "lost to follow up", which was better than failure, then there was no statistically significant difference in overall outcome when comparing nurse and SHO groups.

There were no surgical complications in either group.

\section{PATIENT SATISFACTION}

Nurse treatment was associated with a high level of patient satisfaction. Patients receiving I\&C by a nurse reported significantly lower pain scores compared with the SHO group. They were also more satisfied with the explanation of their diagnosis and treatment and more satisfied with their treatment overall (Table 4).

costs

Unit costs and wages are shown in Table 5.

MARGINAL COST OF APPOINTMENTS

Assuming that each appointment lasted 20 minutes on average, the labour and disposables cost $£ 9.73$ for each $I \& C$ performed by a nurse 
Table 4 Patient satisfaction at most recent visit

\begin{tabular}{|c|c|c|c|}
\hline Patient satisfaction & $\begin{array}{l}\text { Patients treated by a } \\
\text { nurse }\end{array}$ & $\begin{array}{l}\text { Patients treated by } \\
\text { an SHO }\end{array}$ & $p$ Value \\
\hline Mean pain score in $\mathrm{cm}(\mathrm{SD})$ & $1.7(2.0) \mathrm{n}=30$ & $3.8(2.7) \mathrm{n}=23$ & 0.003 \\
\hline \multicolumn{4}{|c|}{ Q: "How adequate was the explanation } \\
\hline of your diagnosis?" (\%) & $\mathrm{n}=43$ & $\mathrm{n}=29$ & 0.001 \\
\hline Very well explained & 58 & 24 & \\
\hline Well explained & 40 & 52 & \\
\hline Badly explained & 0 & 14 & \\
\hline Not explained & 2 & 10 & \\
\hline \multicolumn{4}{|c|}{ Q: "How adequate was the explanation } \\
\hline of your treatment?" (\%) & $\mathrm{n}=43$ & $\mathrm{n}=29$ & 0.003 \\
\hline Very well explained & 61 & 31 & \\
\hline Well explained & 35 & 45 & \\
\hline Badly explained & 5 & 14 & \\
\hline Not explained & 0 & 10 & \\
\hline \multicolumn{4}{|c|}{$\begin{array}{l}\text { Q: "Overall how do you rate the } \\
\text { treatment you received at your last }\end{array}$} \\
\hline visit?" (\%) & $\mathrm{n}=43$ & $\mathrm{n}=29$ & 0.05 \\
\hline Very good & 81 & 52 & \\
\hline Good & 16 & 35 & \\
\hline Bad & 2 & 14 & \\
\hline Very bad & 0 & 0 & \\
\hline
\end{tabular}

$\mathrm{p}$ Values relate to Mann-Whitney tests on ordinal variables and $\chi^{2}$ tests or Fisher's exact tests on categorical variables.
COST EFFECTIVENESS

The marginal cost of treatment of the 60 patients seen exclusively by a nurse was $£ 11.56$ per patient treated and $£ 9.91$ per cyst treated. The equivalent cost for the 39 patients treated exclusively by a SHO was $£ 12.41$ per patient treated, and $£ 12.10$ per cyst treated.

If all 129 patients are considered there were 146 cysts with a marginal cost of $£ 13.66$ per patient treated, and $£ 12.07$ per cyst treated.

\section{Discussion}

The lack of formal randomisation in this study means that bias cannot be excluded when comparing nurse and SHO treatment. This study does, however, provide evidence that nurse treatment of chalazion is safe, effective, and acceptable to patients. In 78 nurse I\&Cs there were no surgical complications and there was no significant difference in overall clinical outcome when compared with the usual treatment strategy - that is, treatment by a junior doctor. The response to questions about explanation of treatment and diagnosis also suggest that a senior nurse is able to communicate well with patients and deliver relatively comfortable surgical treatment. These factors may help explain the high level of patient satisfaction with nurse treatment.

Senior nurse wages are higher than that of an SHO, and the cost of each patient's appointment was subsequently higher. However, nurse treatment was more cost effective as patients were less likely to require a return visit and more likely to receive cheaper (that is, conservative) treatment. Despite this apparent preference for conservative therapy, which had a lower success rate than $I \& C$, nurse treatment had a similar overall success rate to that of SHOs. By treating relatively larger numbers than any given SHO it may be that a senior nurse becomes more skilled in deciding which cysts will respond to conservative therapy and which require $I \& C$.

By using marginal cost analysis, cost trends could be more easily compared between nurse and SHO groups as cost differences will not be masked by capital costs, depreciation, and maintenance. The cost analysis presented in this paper therefore underestimates the true cost of treating each cyst.

The main purpose of this study was to evaluate prospectively the outcome of treatment of chalazion for all patients attending a secondary referral centre. On selected patients I\&C of chalazion is an effective treatment for almost three quarters of cysts while just under one third of those treated conservatively will resolve within 3 months.

both SHO and nurse, there were 60 patients treated exclusively by a nurse and 39 patients treated exclusively by an SHO. The 60 patients treated exclusively by a nurse had between them 88 visits and 70 cysts (1.26 visits per cyst). The 39 patients treated exclusively by a SHO had between them 52 visits and 40 cysts (1.30 visits per cyst). Nurse treatment was conservative in 35 visits and surgical in 53. SHO treatment pattern was 17 conservative, 35 surgical.

We wish to thank David Hitchin from the computing service at Sussex University who provided invaluable assistance in the statistical analysis of the clinical data and Denise Mabey for reviewing the manuscript.

1 McDonnell PJ. How do general practitioners manage eye disease in the community? Brf Ophthalmol 1988;72:733-

2 Epstein GA, Putterman AM. Combined excision and drainage with intralesional corticosteroid injection in the treatment of chronic chalazia. Arch Ophthalmol 1988;106: 
3 Jacobs PM, Thaller VT, Wong D. Intralesional corticosteroid therapy of chalazia: a comparison with incision and curettage. Br f Ophthalmol 1984;68:836-7.

4 Prasad S, Gupta AK. Subconjunctival total excision in the treatment of chronic chalazia. Indian $\mathcal{f}$ Ophthalmol 1992;40:103-5

5 Cottrell, DG, Bosanquet, RG, Fawcett, IM. Chalazions: the frequency of spontaneous resolution. BMF 1983;287:1595.

6 Garrett GW, Gillespie ME, Mannix BC. Adrenocorticosteroid injection vs conservative therapy in the treatment of chalazia. Ann Ophthalmol 1988;20:196-8.
7 Bohigian, GM. Chalazion: a clinical evaluation. Ann Ophthalmol 1979;11:1397-8.

8 Perry HD, Serniuk RA. Conservative treatment of chalazia. Ophthalmology 1980;87:218-21.

9 Laing A. Minor surgery: an extended role for ophthalmic nurses in the United Kingdom. Insight 1999;24:5-9.

0 Mehta DK. British national formulary. 36th ed. London: Royal Pharmaceutical Society of Great Britain/BMA, 1998.

11 Welcan UK. Workload measurement system for pathology: manual with schedule of unit values. Cardiff: HMSO, 1990. 